\title{
Against the Grain: Therapeutic Judging in a Traditional Family Court
}

Vicki Lens

The last several decades have seen a proliferation of specialized courts, including within the family court system, that deviate from the adversarial model, and that rely on therapeutic jurisprudence and other problem-solving techniques. Whether and how traditional family courts can incorporate the best practices of these specialized courts is a largely understudied area. Drawing from ethnographic observations of a traditional urban family court, this study finds that some judges are able to transform nontherapeutic courtrooms into therapeutic ones despite obstacles. These "against the grain" actors, who act contrary to the institution's dominant norms and practices, demonstrate how therapeutic jurisprudence and other problem-solving techniques can be utilized in traditional courtrooms.

\section{INTRODUCTION}

The adversarial system is often unsuited for unraveling and remedying societal ills that spill into the courtroom, especially when rehabilitation rather than punishment is the goal. The result has been a proliferation of specialized courts, including family treatment courts (FTCs), drug courts, and mental health courts, that deviate from the adversarial model and use a problem-solving approach, often relying on therapeutic jurisprudence techniques. The abundance of research on such courts has demonstrated their effectiveness (see, e.g., Aos, Miller, and Drake 2006; Latimer, Morton-Bourgon, and Chretien 2006; Green et al. 2007; Worcel et al. 2008; Downey and Roman 2010; Castellano 2011; Rossman et al. 2011; Bruns et al. 2012). Specialized courts, however, are unlikely to replace traditional courts, which still handle the vast majority of cases involving such social problems as child maltreatment, drug abuse, or mental illness. Whether and how traditional courts can incorporate the best practices of problem-solving courts is a largely understudied area. This ethnographic study of an overburdened and underresourced traditional urban family court examines the ways in which some judges incorporate a more therapeutic approach.

First, the literature on problem-solving courts is reviewed, including how they differ from traditional courts, what methods and practices they use, and what constitutes best practices. The pivotal role of the judge is also examined. Drawing from ethnographic data, the ways in which some judges transform a nontherapeutic

Vicki Lens is an Associate Professor at Columbia University, School of Social Work and may be contacted at vicki.lens@columbia.edu. This research has human subjects approval (Columbia University IRB \# AAAI1826). 
courtroom into a therapeutic one is explored. Theoretical and practical implications are then discussed.

\section{PROBLEM-CENTERED COURTS AND THE THERAPEUTIC APPROACH}

Problems such as substance abuse, child maltreatment, and criminality connected to mental illness require a court to do more than decide a dispute or assign guilt. Often, they require behavioral interventions, especially if recidivism is to be avoided or families repaired. In recognition of this, specialized courts were created with a very different mission and approach than traditional courts. The first such specialized court was the family court, established in the early part of the twentieth century, first to adjudicate juvenile delinquency cases, and then in the 1960s expanded to cover other family issues, including private matters involving divorce and custody and public matters regarding child maltreatment (Babb 1998). Envisioned as a hybrid of the legal and social, it incorporates aspects of the adversarial system, including its focus on due process, while also emphasizing collaboration over conflict, and rehabilitation over punishment.

More recently, specialized courts have proliferated in other areas where social and behavioral issues are intertwined with legal transgressions. Among the most common specialized courts are drug treatment courts, where drug offenders receive rehabilitative services as an alternative to prison, and mental health courts, where people whose mental illness manifests in criminal acts, usually misdemeanors, are treated for their illness in lieu of punishment. Significantly, this judicial trend has also infiltrated family courts, including FTCs, where substance-abusing parents who have abused or neglected their children receive intensive treatment and monitoring.

The creation of FTCs within an already specialized venue suggests the unfulfilled promise of family courts. Virtually since their inception, family courts have been widely criticized on several measures, including court inefficiencies and delays, judges insufficiently attuned to the social and psychology complexity of family strife, and failing to ensure essential services and treatment (Kahn 1953; Babb 1998, 2014; Spinak 2002). As one commentator succinctly noted: "As a problem solving court, Family Court has been remarkably unsuccessful” (Spinak 2008, 260). Traditional family courts thus have much to learn from the latest iteration of problem-solving courts.

\section{The Characteristics of Problem-Solving Courts}

Outwardly, specialized problem-solving courts and traditional courts look the same; both take place in a courtroom with the usual actors-judges, lawyers, and respondents. However, the dialogue and dynamics are very different. In problemsolving courts, providing treatment and services, not adjudicating guilt, are the main focus. Collaboration, rather than conflict, is stressed (Winick 2002-2003; Fay-Ramirez 2015). Teamwork is emphasized over winning legal arguments, and 
social services workers are more likely to participate as "treatment experts" rather than as legal witnesses (Castellano 2011, 487). Sanctions are available, but used sparingly, at least initially, as an educational and reflective tool rather than a punitive one. More common are rewards for good behavior rather than sanctions for bad behavior (Fay-Ramirez 2015).

While the first problem-solving courts, drug courts, were initially envisioned as a solution to case overload in traditional criminal courts, over time they shifted to a more therapeutic approach (McCoy 2003; Spinak 2008), and while not all problem-solving courts are guided by the philosophy of therapeutic jurisprudence (TJ), this approach exemplifies some of these courts' best practices, notably in the mental health courts. TJ views legal rules and procedures and legal actors as therapeutic or antitherapeutic agents that affect participants' psychological well-being. The tools of TJ are especially suited to problem-solving courts because they draw from the psychological and behavioral sciences for motivating positive behaviors. They include such practices as creating a respectful, empathetic, nonpaternalistic, and supportive environment where participants are actively engaged in the decision-making process and are persuaded rather than coerced into making behavioral changes (Winick 2002-2003). As a court-based "public health approach to social and behavioral problems," TJ is a natural, if not always utilized, fit with problem-solving courts (Winick 2002-2003, 1061).

While less adversarial than traditional courts, problem-solving courts are still cognizant of due process (Wexler 1993). Like TJ, procedural due process emphasizes how courts treat people, and hence provides another model for positive courtroom behavior. It focuses on four elements: voice, neutrality, respectful treatment, and trustworthiness (Tyler 2006). Voice means the opportunity to tell one's story, to contribute actively to, and shape, the narrative of events. Neutrality requires an unbiased decision maker who is transparent about how decisions are made. Respect means dignified and courteous treatment. Trustworthiness requires expressions of benevolence, sincerity, and concern. Thus, like TJ, protecting the dignity of persons is a core value and a guiding principle (Perlin 2013).

Both TJ and an enhanced focus on procedural due process are considered to have positive behavioral affects. A respectful, inclusive environment engenders trust in legal authorities, and hence is more likely to lead to compliance with court orders (Tyler 2006). Similarly, TJ, with its emphasis on support, empathy, and respect, encourages constructive and beneficial courtroom interactions (Winick 2002-2003). Thus problem-solving courts often combine aspects of both (Poythress et al. 2002; Perlin 2013).

As in traditional courts, problem-solving judges play a pivotal role as the choreographers of the proceedings. However, they are expected to read from a different script than traditional judges, and one more aligned with TJ than the adversarial system. While traditional judges strike a passive, neutral pose, the ideal problemsolving judge is active and engaged, displaying compassion and empathy (Nolan 2002). They are more likely than traditional judges to speak directly to respondents rather than their attorneys. They also hit a different note, talking in conversational, rather than legal, tones (Fay-Ramirez 2015). Discussions of social and behavioral issues are de rigueur, while legal talk is held to a minimum. 


\section{The Effectiveness of Problem-Solving Courts}

The effectiveness of problem-solving courts has been well studied, especially the first such courts, the drug courts. Overall, the results are positive, with participants having lower rates of recidivism than offenders who did not participate in drug courts (Aos, Miller, and Drake 2006; Latimer, Morton-Bourgon, and Chretien 2006; Downey and Roman 2010; Rossman et al. 2011). Reduced drug use and other psychosocial benefits have also been reported (Rossman et al. 2011). Mental health courts have also shown positive results, with some studies showing a drop in both recidivism and psychiatric hospitalizations and other psychosocial benefits (O'Keefe 2006; for a summary of recent findings, see Cummings 2010, 299-300). FTCs have been less studied, but the evidence to date also suggests positive outcomes. Specifically, several studies have shown that FTCs resulted in shorter foster-care placements and a greater likelihood that children would be returned to their parents than children in traditional courts (Green et al. 2007; Worcel et al. 2008; Bruns et al. 2012).

One important exception is a study conducted on an FTC located in the same court system, the New York City Family Court, as the instant study. Picard-Fritsche et al. (2011) found children took longer to have their cases resolved, and were significantly less likely to be reunified with their families, than in the traditional family court. Their study, however, identified an important variable in the success or failure of specialized courts, and courts overall - the judge. Because the FTC judges in their study also handled similar cases in the traditional family court, they were able to tease out the "judge effect." They found that "the presiding judge in the case has more influence over respondent perceptions [of their court experience] than whether or not they enrolled in the FTC" (Picard-Fritsche et al. 2011, vi).

The judge effect is a well-known and well-documented phenomenon. While many variables affect respondents' experiences in court and case outcomes, there is no doubt that judges play a starring role. Draped in black robes and physically elevated over other court actors, their authority, moral and otherwise, is readily observable. What they say and do can influence a respondent's behavior.

Studies of other problem-solving courts confirm that judges are one of the most significant variables in the success or failure of such courts. In one of the largest studies of drug courts to date, the judge was the single biggest influence on the outcome, with judicial praise, support, and other positive attributes translating into fewer crimes and less use of drugs by participants (Rossman et al. 2011). Similarly, in a study of a drug court that measured behavioral changes through drug-test results, positive supportive comments by the judge were correlated with fewer failed drug tests, while negative comments led to the opposite, and neutral comments had no effect (Senjo and Leip 2001). A qualitative study based on interviews with drug court respondents revealed the dynamics at work, with respondents reporting that the ritual of appearing before a judge and receiving support and accolades, and "tough love" when warranted and reasonable, helped them stick with court-ordered treatment (Farole and Cissner 2005; see also Satel 1998).

Consequently, even a well-resourced problem-solving court may not work if the judge fails to adopt TJ and other problem-solving strategies effectively. As Maze and Hannah (2008) found in their qualitative study of a therapeutic juvenile 
dependency court for domestic violence survivors, maintaining a therapeutic approach is challenging for even the most well-intentioned judges. As they reported, "most clients interviewed described feeling they were demeaned and treated unfairly by the same dependency judges who expressed a strong desire to empower and support" (Maze and Hannah 2008, 42). Most of the women interviewed reported negative experiences, claiming that the judge did not "listen to their side of the story," that they were not treated with respect, and "were spoken to harshly and treated like children" (Maze and Hannah 2008, 37).

A TJ approach may also erode over time, as Fay-Ramirez found in her ethnographic study of an FTC. Over the year and a half in which the study was conducted, "therapeutic norms disintegrate[d] and more non-therapeutic norms and practices $\mathrm{t}[\mathrm{ook}]$ place" (Fay-Ramirez 2015, 17). Judges who had previously relied on therapeutic options became more punitive. Underlying the shift were the same obstacles that confront traditional family courts, including high caseloads, an inability to offer individualized and flexible rehabilitation services, and staff turnover.

\section{Criticisms of Problem-Solving Courts}

Problem-solving courts are not without controversy. As Nolan (2003) observes, therapeutic justice may crowd out other forms of justice, including due process and the protection of individual rights. Because respondents' behaviors are closely monitored, problem-solving courts may paradoxically invite more coercive, intrusive, and punitive approaches, repackaged in the guise of a therapeutic intervention (Boldt 1998; Nolan 2003; Tiger 2013) Spinak (2010) echoes this concern regarding FTCs, where the enhanced surveillance of respondents' behaviors can both stigmatize and disempower them, especially families of color, who are disproportionally represented in the child welfare system. The emphasis on individual accountability also obscures structural and systemic inequities that deprive poor families of crucial resources, while also impeding community-based responses. Finally, Spinak notes that enhanced court intervention also gives more power to judges, who may not have the skills, training, or temperament to exercise it positively.

Nonetheless, problem-solving courts, and TJ in particular, are significant and promising reforms that Perlin $(2013,23)$ describes as "the best tool available to us to infuse the legal process with needed dignity." While not without flaws, both in theory and practice, such courts offer a viable alternative to the oft-criticized traditional court system, especially when it comes to social and psychological issues. Such courts can also function as "laboratories," with best practices diffused into the traditional court system (Rottman 2000, 26).

Little is known, however, about the use of such practices in traditional courts. This gap is significant for several reasons. First, despite the proliferation of specialized courts, traditional courts are more common. Understanding whether and how TJ and other problem-solving techniques can be harmonized within traditional courts is thus essential. Second, as noted above, specialized courts are not immune, especially over time, from the institutional problems that plague more traditional courts (Fay-Ramirez 2015). Thus, specialized courts can benefit from knowing how 
judges in traditional courts overcome these obstacles. Third, along with TJ and problem-solving techniques, specialized courts typically incorporate enhanced services, additional personnel, and other supports. In contrast, in traditional courts such enhancements are lacking, thus highlighting how much—or how little—a judge can do without them.

Drawing from ethnographic observations, this study explores whether and how judges in a traditional family court employ more collaborative problem-solving techniques, including TJ. The study's findings - that some judges are able to transform nontherapeutic courtrooms into therapeutic ones despite many obstacles-have both practical and theoretical implications. Practically, they suggest ways in which TJ and other problem-solving techniques can be infused and sustained, despite institutional obstacles, with judges being the key to such efforts. Theoretically, they add to our understanding of variations among institutional actors, including "against the grain" actors who act contrary to an institution's dominant norms and practices.

\section{METHODOLOGY}

The study draws on data from a family court located in a borough of New York City. The data are the result of a focused ethnography, a type of sociological ethnography that examines specific and well-defined interactions, acts, or social situations in the field rather than an entire system or culture (Knoblauch 2005). Focused ethnography is characterized by relatively short-term field visits and intensive data collection to observe specific structured events or activities. It is especially suited to the observation of courtroom interactions, which are a form of structured social interaction bounded in space and time, with a well-defined beginning and end and cast of characters.

The borough where the study was conducted has the largest percentage of children living in poverty-over 40 percent-in the city, and handles more than 3,000 cases of child abuse and neglect annually (New York City Family Court 2010). Ninety-four child welfare and abuse proceedings were observed over a one-year period between 2012 and 2013, with forty-six observations conducted by the author, and forty-eight conducted by a research assistant. During the period of the observations, nine judges were assigned to the family court. Eight of the nine judges were observed multiple times over multiple observation days and, with one exception, were observed by both the research assistant and the author, at different times. The use of two researchers observing the same site allowed observations to be crosschecked, thus increasing the trustworthiness of the data (Erlandson et al. 1993). The research was approved by an institutional review board.

Judges were assigned cases randomly, and cases were not distinguished by level of severity. Thus, each judge's caseload was similar to every other judge's. Seven judges were female, of whom one was African American. The one male judge observed was Latino. The length of service on the bench ranged from one year to sixteen years, with an average length of service of seven years.

Initially, all types of proceedings involving child abuse and neglect were observed, including initial intakes, emergency removal hearings, fact-finding 
hearings, where charges of abuse or neglect are adjudicated, and dispositional or permanency planning hearings, where decisions are made as to where the child will live. Initial observations revealed a distinction between formal court processes, such as the taking of testimony, and less formal ones, where after a charge of maltreatment was adjudicated or admitted, court actors discussed the family's progress and service needs. This study focused on the latter because they were more likely to involve rehabilitative efforts than adjudication.

During the hearings, a detailed log was maintained, recording both what was said (as much as could be captured) and other observations. These other observations include physical descriptions of the parties and the environment of the room; obvious states of emotion (e.g., anger, crying, laughter); the parties' demeanor, tone, and style (e.g., authoritarian, conciliatory, antagonistic); and quality of personal interactions (e.g., friendly, hostile, apathetic). Routine and standardized data for each hearing observation were also recorded. These include the parties present, the issue that prompted the hearing, and the length of the hearing. Field jottings and observations were transferred into full field notes immediately after actual observations. In-process memos were used to "identify and develop analytic themes" (Emerson, Fretz, and Shaw 1995, 100).

The first set of findings from this study focused on two core aspects of court interaction: participation and compliance. It asked how judges encouraged or inhibited a parent's participation and what strategies and tactics they used to secure a parent's compliance with court orders. The initial data were analyzed using thematic analysis, which has been defined as a "method for identifying, analyzing and reporting patterns (themes) within data" (Braun and Clark 2006, 79; Guest, MacQueen, and Namey 2012). This analysis revealed two very divergent approaches, with some judges discouraging participation and using harsh methods to secure compliance, and other judges using a softer, more therapeutic and collaborative approach (Lens forthcoming). This analysis builds on the latter finding, and seeks to understand, in greater depth and detail, the strategies, rhetorical and otherwise, that such judges used to inject therapeutic techniques into a traditional courtroom.

For this analysis, the previously coded excerpts that indicated a more therapeutic approach were identified and grouped together. The unit of analysis was each interaction between judges and individual parents. Examples of codes that indicated a therapeutic approach included "social lubricants," when a judge greeted the parent by name, "decision-making dialogues," where parents were included in discussions about how to help the family, and "support and praise," when a judge praised or complimented a parent. These coded excerpts were reanalyzed, along with the original field notes in which they appeared, to further delineate the properties and dimensions of therapeutic judging as practiced by the judges. The codes and themes were also compared to the literature on therapeutic jurisprudence techniques. For example, that literature describes how judges use "a more conversational and active role when interacting with courtroom clients" (Fay-Ramirez 2015, 210), a technique reflected, and further refined, in the reanalyzed coded excerpts.

Data sessions were also conducted between the author and a research assistant, who, as noted above, had also conducted observations. The purpose of these 
meetings was to compare analysis and interpretation of the data, and to reach consensus on the defining themes and their properties and dimensions.

\section{FINDINGS}

Courtroom interactions are ritualized and skilled conversations structured by legal, institutional, and social rules. Legally, the rules of the adversarial process dictate who has the authority to direct the conversation (the judge) and who can speak for others (attorneys speak for their clients). This means that in family court, where parents are represented by an attorney, legal talk often substitutes an attorney's voice for the parent's.

Courtrooms are also social institutions with specific goals. In family court, the goal is to "fix" families and protect children, either by removing children from the home or ordering rehabilitative and other services. Conversations are constrained by these institutional goals (Heritage 1997). Thus, overlaid over legal talk is institutional talk, including bureaucratic buzz words, such as "permanency planning" and other sometimes indecipherable references to the legal stages of the proceedings. As the only noninstitutional player, the parent is an outsider and is expected to defer to the institutional players' knowledge and expertise. Such deference has a coercive tinge; noncooperation can result in a loss of parental rights.

Courtrooms are also a form of public social ritual, and as such a performance (Goffman 1972). As Goffman explains, a main goal of public performances is to avoid social judgments that elicit embarrassment or shame. This has special salience for parents in child maltreatment proceedings, who already come from highly stigmatized groups (people of color, the poor), and who are accused of harming their children, one of the most stigmatizing of acts. As Jennifer Reich (2005) documented in her study of the family court system, child maltreatment cases are often rituals of social control, stigma, and stereotyping.

In more therapeutic courts, these legal, institutional, and social rules can be bent. Judges and respondents are encouraged to talk directly with one another in more conversational tones. While the institutional actors' power over respondents remains the same, it is channeled more constructively toward individualized help and support. Similarly, while the stain of stigma cannot be erased, efforts are made to lessen its sting.

In traditional courts these obstacles remain. It is thus not surprising, as the first set of findings found, that many of the judges acted in nontherapeutic ways (Lens forthcoming). Although as described above, family courts were envisioned as both adjudicative and rehabilitative forums, judges often did not employ specialized problem-solving or therapeutic techniques. They spoke about, and not to, parents, and at times silenced parents who wished to speak. When stressing compliance with court orders and treatment plans, they lectured, admonished, and even yelled at parents. Overall, they treated parents, usually mothers, punitively and paternalistically. This attitude sometimes extended to other court actors, including social workers and attorneys, who were publicly admonished for perceived professional failings. In short, they demonstrated many of the characteristics associated with 
overburdened, underresourced courts where judges have little time, and hence often little patience, for adopting a more measured, collaborative, and problem-solving approach.

However, some judges were more apt than others to infuse their courtrooms with therapeutic moments. This softer, gentler, and more respectful approach existed on a continuum, with one judge using therapeutic techniques virtually all of the time, in stark contrast to the approach described above, and several others judges incorporating such techniques to varying degrees, while overall avoiding a harsher and more paternalistic tone.

Differences in judicial styles are not unexpected. As studies of judicial behavior note, judges differ in their approach, including their personal style and how they communicate (Conley and O'Barr 1990; Mack and Anleu 2010). It is also not surprising, given family court's rehabilitative mission, that some judges acted therapeutically. These judges' techniques demonstrate how traditional family courts can function as they were originally envisioned. How, seemingly against the odds, these judges spun moments of calm out of chaos, and created a supportive less stigmatizing environment is described next.

\section{Micro Behaviors/Macro Consequences}

In seemingly small ways but with large social payoffs, judges with a therapeutic bent created more inclusive and respectful environments. They were more attuned than nontherapeutic judges to positive social rituals. In less therapeutic courtrooms, signals were sent suggesting that parents were interlopers. As one example, while attorneys were addressed by their formal names with the appellation "Mr." or "Ms.," parents were not. When addressed directly by the judge, they were often called "Ma'am," and when spoken about they were referred to as "the mother" or "the father," thus distinguishing them from institutional insiders. The use of nouns rather than proper names also constructs parents as objects to be worked on, rather than as individuals to be listened to.

In contrast, therapeutic judges were attuned to social conventions that signal respect and inclusiveness. They greeted the mother or father by name, and used social niceties to put them at ease, as in the following example: "Ms. H., How are you? You're looking well." Conversely, to signal their distance from the institutional insiders, they might greet them not by name, which indicates familiarity, but by saying "Good afternoon, counsel."

Ordinary routines, such as setting the next court date, were also handled differently. Child maltreatment proceedings require multiple appearances at specific intervals as a family's progress is monitored. Finding a mutual time is a perennial challenge in overworked courtrooms. Often, five or more institutional actors, including the judge, attorneys, and caseworkers, must sync their busy schedules. Court proceedings usually ended with the judge calling out dates and the various institutional actors checking their calendars and agreeing or not to the proposed date. More therapeutically attuned judges included parents in this ritual, asking about their work schedules and convenient dates and times. In contrast, 
nontherapeutic judges excluded parents and simply told them what date to return to court, no questions asked. The not-so-subtle social message was that their time is not valued, their preferences not worth respecting.

Ordinary irritations were also handled differently by therapeutic judges. An illustrative example was the way such judges treated common courtroom irritants, in particular a parent's late arrival. Late parents were a constant source of annoyance to judges because of the cascading effect on their daily calendar, which was difficult to complete under the best of circumstances. While reasons for lateness varied, sometimes it was caused by the vagaries of the security line at the building entrance, which often snaked around the building, spilling outdoors. (There was no line for courtroom personnel, who gained entry by flashing their identification cards.) The line's length was also unpredictable, and varied from day to day. Nonetheless, some judges explicitly rejected a slow security line as a valid excuse, and used a parent's lateness as an opportunity to berate them.

In contrast, therapeutically attuned judges were more likely to overlook a parent's lateness, and welcome rather than chastise late-arriving parents. One judge even turned a parent's lateness into a therapeutic moment, when a father arrived late to court because, as his attorney explained, he saw a man he had an altercation with and was afraid to enter the courthouse. When the father arrived ten minutes later, the judge interrupted the proceedings to welcome him. Leaning forward on her desk with a slight smile, she said to him "Mr. (x) before you arrived, your attorney explained ... the circumstances of you not coming earlier. I think you used pretty good judgment protecting yourself physically and emotionally. I'm proud of you. It's ok that you left and it's ok that you came back. Your attorney will fill you in on anything you missed, ok?"

Overall, therapeutic judges exercised "soft" power rather than "hard" power, staying firmly but gently in control. They spoke in calmer, usually softer, tones than nontherapeutic judges, who were more likely to use harsh tones. They also used modulating words and phrases, such as "thank you" and "would you mind." To create a less formal and more welcoming environment, they alternated legal rituals with social ones. For example, in traditional courtrooms the swearing-in ritual often serves as the parent's first introduction to the courtroom. Cognizant of its foreboding nature, therapeutic judges followed it with a social salutation, and a more informal greeting.

Another distinguishing characteristic of judges with a therapeutic bent was their physical bearing and nonverbal behaviors. Visibly, the black robes all judges wear suggest a certain uniformity. However, any semblance of sameness is easily overcome by other visible cues, including facial expressions, body movements, and posture. Therapeutic judges used nonverbal communication behaviors that subtly conveyed respect, patience, and attentiveness, such as nodding, raising eyebrows and widening eyes, maintaining eye contact, leaning forward, and tilting their head when listening.

In sum, therapeutic judges were acutely attuned to social dynamics and rituals that communicate worthiness or unworthiness, inclusiveness or ostracism. While traditional judges used routine courtroom rituals as instruments of social control, or to send disapproving social messages, therapeutic judges transformed them into 
more supportive and affirming exchanges, from the words they used to their facial expressions and tone of voice.

\section{Bending the Adversarial System}

The adversarial system is often unsuited to the purposes and goals of family court. Especially after a charge of neglect or abuse has been adjudicated or admitted to, and the focus shifts to "fixing" families, legal rules and procedures become barriers, rather than facilitators. At this stage, court appearances are no longer about adjudicating guilt but about a family's functioning. There is less legal talk, and more social and psychological talk, with the dialogue focusing on intimate family matters. Is the mother attending drug treatment? How bad are the side effects from various medications? Are the children doing well in school? When should a parent be permitted to visit a child? Should overnight visits be allowed?

The adversarial system, though, invites, if not mandates, a parent's silence, with attorneys functioning as parents' mouthpieces. Parents' actions, motivations, and social and psychological states are constructed through the words of others. Agency records and reports detail their deeds, and their failures and successes. Attorneys who spend little time with clients are expected to complete or contradict the picture of their clients painted by others. In short, parents must prove their worth, but without using their own voice, or their own words.

Therapeutic judges were more likely than traditional judges to acknowledge a parent's missing voice, and remedy it. They did not insist that all dialogue flow through the institutional actors, and instead engaged parents directly, even overriding their attorneys' protective and silencing gestures. They participated in both informational and decisional dialogues with parents. For the former, they asked parents to fill in facts, such as when they attended an appointment, or how they were handling a medication's side effects, or how many days they were clean from drugs. This seemingly routine asking and recording of information leavened, if only a little, the greater deference usually given to agency records and reports, while making parents the authors of their own lives.

Similarly, therapeutically inclined judges were more likely to treat parents, rather than the institutional actors, as an authority on family matters and decisions. In an illustrative example involving a disputed visitation schedule, the judge engaged the parent directly, soliciting both facts (when the father visited) and preferences (which holidays each parent prefers). In another case, the judge had an extended dialogue with the mother about choosing a residential treatment center for a child. In a third example, the judge and mother discussed a child's mental health needs, with the mother voicing concerns about her son's "anger issues" directly to the judge, rather than through her attorney, who played a more peripheral role. The judge ordered counseling for the child, adding that the parent "of course should be kept aware of his progress," thus solidifying the primacy of the parental role.

In sum, therapeutic judges struck a conversational and inclusive tone, engaging parents directly. Although this is by design in therapeutic courts, it is less likely to 
occur in traditional family courts where the adversarial system dictates that most dialogue flows through the attorneys. Therapeutic judges were willing to short circuit these institutional and legal norms and practices and interact more personally with parents.

\section{Offering Support and Praise}

A common feature of therapeutic courts is the use of psychological insights and methods to motivate behavioral changes. Instead of treating individuals as deviant and condemning their behavior, therapeutic courts employ healthy doses of respect, empathy, and forgiveness. This approach is bolstered by enhanced access to treatment resources, individualized treatment plans, and a collaborative team of community-based and institutional professionals. Traditional courts suffer from a dearth of all of these, and the additional burden of high caseloads. Lacking both time and resources, judges in a traditional courtroom seemingly have little incentive to employ a therapeutic approach.

Despite these obstacles, some judges employed therapeutic techniques during "big" moments, such as when a parent's behavior and progress was being assessed. Although surrounded by all the accoutrements of the adversarial system, they created a supportive rather than antagonistic environment. Such moments are ripe for stigma and shame, as intimate details of drug use and other negative parental behaviors are publicly discussed by multiple institutional actors as a usually silent parent sits in their midst. More often than not, the lone parent is a female poor person of color, thus unspoken issues of race, class, and gender also tinge these proceedings. In the following vignette, the judge, in a brief seven-minute encounter, transformed the courtroom into a therapeutic space rather than a stigmatizing one:

The judge began the proceedings by looking directly at the mother, with a slight smile on her face, and saying "Ms. (x) how are you? You're looking well." The mother responded that she was well, and the judge continued with a series of questions, directed to both the mother and the mother's attorney, about how the drug treatment program was working out and how her son was doing. The mother noted she was 172 days clean. In response the judge loudly applauded, smiling and gestured for others in the room to also applaud, which all did. The judge then leaned forward, and commended her for her sobriety: "I want to emphasize these clean days. And I'd like you to do the same." The judge then resumed questioning as to methadone dosage and course of treatment. When the mother noted that the dosage was being stepped down, the judge emphasized going at a comfortable pace "No celestial brownie points for doing things faster than you are comfortable with."

The judge then asked the mother how her son was doing, adding "will you please bring a picture of $[\mathrm{x}]$ next time?" She also asked her preference for the next date: "Are there some days that are easier for you than others?" As the judge brought the proceeding to a close, she asked the mother "if [the son] exhibits any behavioral problems let's try and address 
them before they get worse, okay?" The mother agreed and thanked the judge as she left.

From the judge's initial greeting (How are you? You're looking well) to her request for a picture of the son, the mother was treated like an individual rather than a case number. She responded in kind, animatedly providing details of her treatment without any apparent shame. A potentially stigmatizing encounter was transformed into an occasion of praise, which enveloped the whole courtroom. The judge's suggestion that the mother set her own pace ("No celestial brownie points for doing things faster than you are comfortable with") positioned her as autonomous and competent enough to make decisions about her treatment. The use of the inclusive us (let's try and address [any problems with the son]) suggested a commitment to work together, equally, on any problems.

Overall, and in contrast to more traditional judges, who talked little or sternly to parents, therapeutic judges injected morsels of support, respect, and empathy at opportune times. As an example, during an admission of guilt, where parents are asked a routine series of questions and told their rights, the judge was highly attuned to the distraught mother's emotional state. She told the mother, "[i]t's not a punishment, though it may feel to you like a punishment. It's the court's job to help you and your family," also later telling her, "I know this is difficult for you." In another example, the judge asked a mother if she was satisfied with court-ordered services, a straightforward but rarely asked question in family court, where parents are expected passively to accept and comply with whatever services are offered. It is a respectful gesture that suggests the parent has the power to judge others, and not solely to be judged by them.

This more therapeutic approach often extended to the institutional actors, including attorneys, and especially caseworkers. In the hierarchy of institutional actors, child welfare caseworkers occupy the lowest rung. They have less education than the higher-status attorneys, who outnumber them in the courtroom. They often come from the same disenfranchised group-women of color-as parents. While they are much more likely than parents to participate, like parents, what they have to say is often communicated through an attorney. Also like parents, their behavior and competency is under a microscope. Agency missteps, such as incomplete reports, missing documents, or inadequate monitoring of parents, are often attributed to them.

While nontherapeutic judges were likely to admonish and criticize caseworkers harshly, therapeutically inclined judges were more conciliatory and respectful. In a contrasting example, a nontherapeutic judge, upset that the agency had not held a crucial conference to "explore" what services the family needed, told the caseworker in an impatient and irritated voice, "explore means you are doing nothing. ... I don't make my rules based on your conferences. If I waited for [the agency] to do conferences the cases will take years. I'll give you a week and a half for the conference."

A therapeutic judge, confronted with a similar problem, first looked for the reason: "I can see there was another caseworker, so I can see how that may explain the insufficient efforts." Speaking calmly and deliberatively, the judge said: "It's 
been more than two months. Something should have been done. This needs to be done before the permanency hearing." In contrast to the example above, she did not use the misstep to criticize the worker, while firmly but nicely directing the caseworker to act.

Therapeutic judges also strove to bring institutional actors and parents together, rather than reinforcing their adversarial nature of the relationship. In one such example, after a caseworker updated the court on the family's progress, the attorney for the children interjected, "I just want to express ... I'm very pleased with [how the case has proceeded]." The judge built on this comment, telling everyone: "You've all worked very diligently ... attorneys, caseworkers." She then asked that the mother (waiting outside the courtroom with the children) be brought in, "so we can acknowledge her efforts."

In sum, judges who were more therapeutically inclined created a nonadversarial, supportive, and respectful environment encompassing both the institutional actors and parents. They did so quickly and efficiently, and without creating any courtroom bottlenecks. Instead, they saved time because treating parents kindly rather than harshly was less likely to trigger time-consuming and disruptive emotional outbursts.

\section{DISCUSSION}

The ideal judge, as described by codes of judicial conduct, is unreadable, detached, and impersonal (Landsman 1983). Facts, not feelings, guide decisions; passion and personality have no place. The legitimacy of the adversarial system rides on neutrality, which requires judges to be detached. Judges, though, are not interchangeable. As the extensive literature on judicial styles attests, judges vary in how they view the law and run their courtrooms (see, e.g., Conley and O'Barr 1990; Mack and Anleu 2010).

These differences are, in part, a function of the highly discretionary and autonomous nature of judging. More significant, though, than these differences, is the context within which they occur. Child maltreatment cases involve individuals stigmatized on the multiple levels of race, gender, and poverty. African American children are overrepresented in the child welfare system, and poor people are more likely than the affluent to be accused of child maltreatment (Courtney et al. 2005; Boyd 2014). They are also more likely to be receiving welfare, a deeply seated stigma. Finally, family court respondents are mostly women who have failed at mothering, and hence are subject to "a special form of contempt reserved for mothers, particularly those who are unmarried" (Reich 2005, 10).

It is thus not surprising that parents are more likely than not to be treated harshly, paternalistically, and disrespectfully. As Goffman put it, stigma creates unease and discomfort for all actors, making "for anxious unanchored interaction" (Goffman 1963, 18). Judges are not immune from this discomfort, and can be captured by those same stereotypes, exercising their discretion in ways that reinforce rather than challenge them (Lens forthcoming). Family courts are also bureaucracies and must process a high number of cases quickly and efficiently. Judges' 
encounters with parents are hence episodic and brief, and there is little time to form judgments. A quicker and simpler device is to rely on negative stereotypes as a shortcut (Maynard-Moody and Musheno 2003).

However, as this study's findings demonstrate, some judges chose a different path. Faced with institutional obstacles identical to those confronting their colleagues, including high caseloads, insufficient resources, and challenging cases, and lacking the institutional support available in therapeutic courts, several of the judges chose to employ a therapeutic approach.

From a theoretical perspective, the existence of such judges illustrates the variability within institutions that are often portrayed as monolithic and, in the case of traditional family courts, as ineffective. Notably, these judges went against the grain and did not yield to the negative stereotypes that dominate such courts. They were able to turn "anxious unanchored interaction[s]" into more constructive dialogues. A parallel phenomenon occurs in the welfare bureaucracy, an analogous government institution serving similar (and sometimes the same) disenfranchised people. Sprinkled among the prototypical bureaucrats who exercise their discretion negatively are more kindly and compassionate workers. This occurs on all levels, from the few front-line workers who choose to act as social workers rather than "efficiency engineers" (Watkins-Hayes 2009, 61) to the administrative law judges who hear welfare claims, some of whom act as reformers rather than enforcers (Lens 2013).

The existence of against the grain institutional actors may be explained, in part, by how workers construct their professional identities. All workers start with the same "discretionary toolkits," including the goods and services provided by the organization and the rules and procedures for distributing them (Watkins-Hayes 2009, 56). Workers then customize their toolkits, adding in their own "stylistic devices," drawing from both "their cumulative understandings of clients and the institution" and their own personal, political, and social beliefs (56). The latter factors especially may explain institutional actors who resist institutional and societal norms. However, there is no straight line between the two. In this study, markers of less conventional political and social beliefs, such as previous experience as a public interest attorney, did not line up with current judicial style. Nor did markers such as gender play a role, as there was wide variation of judicial styles among the sample, which with one exception was female. Further research is needed to understand what factors foster against the grain institutional actors.

From a practical perspective, the study's findings suggests that therapeutic jurisprudence and other problem-solving techniques can be effectively deployed in even the most overburdened and underresourced of traditional family courts. Such an approach does not necessarily require a specialized court but, in essence, a specialized judge, one versed in therapeutic techniques and willing and able to use them, as were the judges in this study. They engaged directly with parents, rather than through their attorneys. They created collaborative and respectful environments. And they relied on empathy and support, rather than sanctions and threats, to motivate parents and institutional actors alike. In short, the judges' singularly powerful role allowed court processes to be modified to include therapeutic techniques. 
The findings also suggest that family court judges should be selected based on judicial temperament and style, and ability to implement therapeutic techniques. This is equally true for specialized therapeutic courts and traditional ones. As the study by Picard-Fritsche et al. (2011) described above showed, more significant than whether the court was based on a therapeutic model was the respondents' perceptions of the presiding judge. Whether therapeutic judges are born or made, or whether such skills can be taught, or are so innately personal that some judges will invariably be more therapeutic than others, requires further research.

\section{REFERENCES}

Aos, Steve, Marna Miller, and Elizabeth Drake. 2006. Evidence Based Public Policy Options to Reduce Future Prison Construction, Criminal Justice Costs and Crime Rates. Federal Sentencing Review 19 (4): 275-90.

Babb, Barbara. 1998. Fashioning an Interdisciplinary Framework for Court Reform in Family Law: A Blueprint to Construct a Unified Family Court. Southern California Law Review 71: 469-528.

—. 2014. Family Courts Are Here to Stay, So Let's Improve Them. Family Court Review 52 (4): $642-47$.

Boldt, Richard. 1998. Rehabilitative Punishment and the Drug Treatment Court Movement. Washington University Law Quarterly 76 (4):1205-1306.

Boyd, Reiko. 2014. African American Disproportionality and Disparity in Child Welfare: Toward a Comprehensive Conceptual Framework. Children and Youth Services Review 37:15-27.

Braun, Virginia, and Victoria Clarke. 2006. Using Thematic Analysis in Psychology. Qualitative Research in Psychology 3:77-101.

Bruns, Eric J., Michael D. Pullmann, Ericka S. Weathers, Mark L. Wirschem, and Jill K. Murphy. 2012. Effects of a Multidisciplinary Family Treatment Drug Court on Child and Family Outcomes: Results of a Quasi-Experimental Study. Child Maltreatment 17 (3): 218-30.

Castellano, Ursula. 2011. Courting Compliance: Case Managers as "Double Agents" in the Mental Health Court. Law $\mathcal{E}$ Social Inquiry 36:484-511.

Conley, John M., and William M. O'Barr. 1990. Rules Versus Relationships: The Ethnography of Legal Discourse. Chicago, IL: University of Chicago Press.

Courtney, Mark E., Amy Dworsky, Irving Piliavin, and Andrew Zinn. 2005. Involvement of TANF Applicant Families with Child Welfare Services. Social Service Review 79 (1): 119-57.

Cummings, John E. 2010. The Cost of Crazy: How Therapeutic Jurisprudence and Mental Health Courts Lower Incarceration Costs, Reduce Recidivism, and Improve Public Safety. Loyola Law Review 56:279-310.

Downey, Mitchell P., and John K. Roman. 2010. A Bayesian Meta-Analysis of Drug Court CostEffectiveness. Washington, DC: Crime Policy Institute.

Emerson, Robert M., Rachel I. Fretz, and Linda L. Shaw. 1995. Writing Ethnographic Fieldnotes. Chicago, IL: Chicago University Press.

Erlandson, David A., Edward L. Harris, Barbara L. Skipper, and Steve D. Allen. 1993. Doing Naturalistic Inquiry: A Guide to Methods. Thousand Oaks, CA: Sage.

Farole, Donald, J., and Amanda B. Cissner. 2005. Seeing Eye to Eye? Participant and Staff Perspectives on Drug Courts. New York: New York Center for Court Innovation.

Fay-Ramirez, Suzanna. 2015. Therapeutic Jurisprudence in Practice: Changes in Family Treatment Court Norms Over Time. Law Eु Social Inquiry 40 (1): 205-36.

Goffman, Erving. 1963. Stigma: Notes on the Management of Spoiled Identity. Englewood Cliffs, NJ: Prentice-Hall.

—. 1972. Relations in Public. New York: Harper \& Row. 
Green, Beth L., Carrie Furrer, Sonia Worcel, Scott Burrus, and Michael W. Finigan. 2007. How Effective Are Family Treatment Drug Courts? Outcomes from a Four-Site National Study. Child Maltreatment 12 (1): 43-59.

Guest, Greg, Kathleen M. MacQueen, and Emily E. Namey. 2012. Applied Thematic Analysis. Thousand Oaks, CA: Sage.

Heritage, John. 1997. Conversation Analysis and Institutional Talk: Analyzing Data. In Qualitative Research: Theory, Method and Practice, ed. David Silverman, 103-47. London: Sage.

Kahn, Alfred. 1953. A Court for Children: A Study of the New York City Children's Court. New York: Columbia University Press.

Knoblauch, Herbert. 2005. Focused Ethnography. Forum: Qualitative Research 6:Art. 44.

Landsman, Stephen. 1983. A Brief Survey of the Development of the Adversary System. Ohio State Law Journal 44:713-39.

Latimer, Jeff, Kelly Morton-Bourgon, and Jo-Anne Chretien. 2006. A Meta-Analytical Examination of Drug Treatment Courts: Do They Reduce Recidivism? Ottawa, ON: Department of Justice.

Lens, Vicki. 2013. Revisiting the Promise of Kelly v. Goldberg in the Era of Welfare Reform. Georgetown Journal on Poverty Law and Policy 21 (1): 43-89.

—. forthcoming. Engaging Parents in Family Court: Lessons from an Observational Study of Child Protection Cases. Journal of Social Work.

Mack, Kathy, and Sharyn Roach Anleu. 2010. Performing Impartiality: Demeanor and Legitimacy. Law $\mathcal{E}$ Social Inquiry 35 (1): 137-73.

Maynard-Moody, Steven, and Michael Musheno. 2003. Cops, Teachers, Counselors: Stories from the Front Lines of Public Service. Ann Arbor, MI: University of Michigan Press.

Maze, Candice L., and Stefanie A. Hannah. 2008. Perspectives on Therapeutic Jurisprudence in Dependency Court in Cases Involving Battered Mothers. Juvenile and Family Court Journal 59 (1): 33-45.

McCoy, Candace. 2003. The Politics of Problem-Solving: An Overview of the Origins and Development of Therapeutic Courts. American Criminal Law Review 40 (4): 1513-34.

New York City Family Court. 2010. Annual Report. New York: New York City Family Court.

Nolan, James L. 2002. Therapeutic Adjudication. Society 39 (2): 29-38.

- 2003. Redefining Criminal Courts: Problem-Solving and the Meaning of Justice. American Criminal Law Review 40 (4): 1541-65.

O'Keefe, Kelly. 2006. The Brooklyn Mental Health Court Evaluation. New York: Center for Court Innovation.

Perlin, Michael L. 2013. "The Judge, He Cast His Robe Aside": Mental Health Courts, Dignity and Due Process. Mental Health Law E Policy Journal 3:1-28.

Picard-Fritsche, Sarah, Jennifer Bryan, Dana Kralstein, and Erin Farley. 2011. The Bronx Family Treatment Court 2005-2010: Impact on Family Court Outcomes and Participant Experiences and Perceptions. New York: Center for Court Innovation.

Poythress, Norman G., John Petrila, Annette McGaha, and Roger Boothroyd. 2002. Perceived Coercion and Procedural Justice in the Broward Mental Health Court. International Journal of Law and Psychiatry 25:517-33.

Reich, Jennifer A. 2005. Fixing Families: Parents, Power, and the Child Welfare System. New York: Routledge.

Rossman, Shelli B., Michael Rempel, John K. Roman, Janine M. Zweig, Christine H. Lindquist, Mia Green, P. Mitchell Downey, Jennifer Yahner, Avinash S. Bhati, and Donald J. Farole, Jr. 2011. What Have We Learned from the Multi-Site Adult Drug Court Evaluation? Implications for Policy, Practice, and Future Research. In The Multi-Site Adult Drug Court Evaluation: The Impact of Drug Courts, ed. Shelli B. Rossman, John K. Roman, Janine M. Zweig, Michael Rempel and Christine H. Lindquist, 251-67. Washington, DC: Urban Institute Justice Policy Center.

Rottman, David B. 2000. Does Effective Therapeutic Jurisprudence Require Specialized Courts (and Do Specialized Courts Imply Specialist Judges)? Court Review Spring:22-27.

Satel, Sally. 1998. Observational Study of Courtroom Dynamics in Selected Drug Courts. National Drug Court Institute Review 1 (1): 43-72. 
Senjo, Scott, and Leslie Leip. 2001. Testing Therapeutic Jurisprudence Theory: An Empirical Assessment of the Drug Court Process. Western Criminology Review 3 (1): 1-21.

Spinak, Jane M. 2002. Adding Value to Families: The Potential of Model Families Court. Wisconsin Law Review 2002 (2): 327-71.

- 2008. Romancing the Court. Family Court Review 46 (2): 258-74.

- 2010. A Conversation About Problem-Solving Courts: Take 2. University of Maryland Law Journal of Race, Religion, Gender and Class 10:113-36.

Tiger, Rebecca. 2013. Judging Addicts: Drug Courts and Coercion in the Justice System. New York: New York University Press.

Tyler, Tom. 2006. Why People Obey the Law. Princeton, NJ: Princeton University Press.

Watkins-Hayes, Celeste. 2009. The New Welfare Bureaucrats: Entanglements of Race, Class, and Policy Reform. Chicago, IL: University of Chicago Press.

Wexler, David B. 1993. Therapeutic Jurisprudence and Changing Concepts of Legal Scholarship. Behavioral Sciences and the Law 11:17-29.

Winick, Bruce J. 2002-2003. Therapeutic Jurisprudence and Problem Solving Courts. Fordham Urban Law Journal 30:1055-90.

Worcel, Sonia D., Carrie J. Furrer, Beth L. Green, Scott W. Burrus, and Michael Finigan. 2008. Effects of Family Treatment Drug Courts on Substance Abuse and Child Welfare Outcomes. Child Abuse Review 17:427-43. 